\title{
Microwave-assisted green synthesis and antimicrobial activity of silver nanoparticles derived from a supercritical carbon dioxide extract of the fresh aerial parts of Phyllanthus niruri L
}

\author{
Mohd Haris ${ }^{1}$, Arvind Kumar ${ }^{1}$, Aftab Ahmad ${ }^{2 \star}$, Mohammed F Abuzinadah ${ }^{3}$, \\ Mohammed Basheikh ${ }^{4}$, Shah Alam Khan ${ }^{5}$, Mohd Mujeeb ${ }^{6}$ \\ ${ }^{1}$ S. D. College of Pharmacy and Vocational Studies, Muzaffar Nagar, UP, India, ${ }^{2}$ Health Information Technology Department, \\ Jeddah Community College, King Abdulaziz University, PO Box 80283, Jeddah 21589, Saudi Arabia, ${ }^{3}$ Department of Medical \\ Laboratory Sciences, College of Applied Medical Sciences, King Abdulaziz University, Jeddah, Saudi Arabia, ${ }^{4}$ Department of \\ Internal Medicine \& Geriatric Medicine, Faculty of Medicine, King Abdulaziz University, Jeddah 21589, PO Box 80215, Saudi \\ Arabia, ${ }^{5}$ Department of Pharmacy, Oman Medical College, Muscat, Sultanate of Oman, ${ }^{6}$ Department of Pharmacognosy \& \\ Phytochemistry, Faculty of Pharmacy, Hamdard University, New Delhi, India
}

*For correspondence: Email: aftab786sa@hotmail.com, mohdmujeeb72@gmail.com

Sent for review: 9 May 2017

Revised accepted: 26 November 2017

\begin{abstract}
Purpose: To synthesize and evaluate the antimicrobial activity of silver nanoparticles (AgNPs) derived from a supercritical carbon dioxide extract of the fresh aerial parts of Phyllanthus niruri.

Methods: The synthesis of AgNPs of a P. niruri extract was carried out in a microwave oven. The extraction was carried out using a supercritical fluid extractor. The AgNPs were characterized by the Ultraviolet-visible (UV-vis) spectral analysis, Dynamic Light Scattering (DLS) zetasizer analysis, Transmission electron microscopy (TEM), X-ray diffraction (XRD) analysis and Fourier transform infrared (FT-IR) spectroscopy. The antimicrobial assays of AgNPs were carried out against different bacterial and fungal strains.

Results: Results of various analytical techniques confirmed the synthesis of AgNPs of a P. niruri extract. The UV-vis spectroscopy showed an intense silver surface plasmon resonance band at 415 NM. The AgNPs had a mean size of $110 \mathrm{~nm}$ in the Zetasizer analysis. TEM images illustrated spherical AgNPs having a mean particle size of $110 \mathrm{~nm}$. The X-ray diffractograms showed peaks at $38.17^{\circ}$, $44.28^{\circ}$, and $64.52^{\circ}$. The average crystallite size of Ag-NPs was found to be $110 \mathrm{~nm}$. FT-IR spectra confirmed the stability of the AgNPs. The AgNPs demonstrated good antimicrobial effects against several tested pathogenic microbes.

Conclusion: An efficiently synthesized AgNPs of P. niruri (SC-CO2) extract has been prepared by a simple, eco-friendly, cost-effective, rapid green chemistry methodology. The AgNPs of P. niruri extract possesses significant antimicrobial properties against the tested bacterial and fungal strains.
\end{abstract}

Keywords: Nanoparticles, Phyllanthus niruri, Supercritical fluid extraction, Microwave, Antimicrobial activity

This is an Open Access article that uses a funding model which does not charge readers or their institutions for access and distributed under the terms of the Creative Commons Attribution License (http://creativecommons.org/licenses/by/4.0) and the Budapest Open Access Initiative (http://www.budapestopenaccessinitiative.org/read), which permit unrestricted use, distribution, and reproduction in any medium, provided the original work is properly credited.

Tropical Journal of Pharmaceutical Research is indexed by Science Citation Index (SciSearch), Scopus, International Pharmaceutical Abstract, Chemical Abstracts, Embase, Index Copernicus, EBSCO, African Index Medicus, JournalSeek, Journal Citation Reports/Science Edition, Directory of Open Access Journals (DOAJ), African Journal Online, Bioline International, Open-J-Gate and Pharmacy Abstracts 


\section{INTRODUCTION}

Nanotechnology is a multidisciplinary and the fastest growing scientific field in material sciences, physics, chemistry, electrical \& chemical engineering, biotechnology and pharmaceutical sciences. Nanotechnology has been used to formulate nanoscale materials with size less than $100 \mathrm{~nm}$ [1].The nanoparticles have broad spectrum application in various scientific disciplines, including pharmaceutical sciences. The silver nanoparticles (AgNPs) was reported to have an excellent antimicrobial activity and many other properties [2]. The synthesis of AgNPs can be achieved by different physical as well as chemical methods like chemical reduction, UVirradiation, photochemical method, electron irradiation and recently by biological routes from microorganisms, enzymes and plant extracts. The biological method has shown an advantage over other methods due to its low cost, environmentally friendly, easy synthesis on a large scale [3,4]. Numerous research articles on the synthesis of AgNPs from the plant extracts have been published in the last decade that clearly highlights their therapeutic potential. Microwave which assisted the biosynthesis of the AgNPs of plant extract offers many advantages. This is the fast and easy way of green synthesis. The lower energy consumption, shorter reaction time and improved yields are the advantages of the microwave assisted synthesis of AgNPs [5,6,7]. Phyllanthus niruri L. (Family: Euphorbiaceae) is an annual small herb which has many folklore uses in the traditional system of medicines. This plant is reported to possess diverse medicinal properties like antioxidant, antiviral, antimicrobial and anticancer activities in the experimental studies that might be due to the presence of alkaloids, flavonoids, tannins, lipids, sterol and lignins $[8,9]$. In the present study, we have explored a simple and green synthetic method for the synthesis of the AgNPs by reducing silver ions available in the silver nitrate solution using supercritical carbon dioxide (SC$\mathrm{CO} 2$ ) extract of $\mathrm{P}$. niruri by a microwave-assisted method.

\section{EXPERIMENTAL}

\section{Chemicals and reagents}

The analytical grade silver nitrate was purchased from Merck, India. Nutrient broth, Mueller Hinton agar (MHA) and potato dextrose agar (PDA) were purchased from Hi-Media Chemicals, Mumbai, India. Double distilled water was used for the preparation of all the aqueous solutions throughout all the stages of this study.

\section{Supercritical carbon dioxide extraction}

The fresh aerial parts of Phyllanthus niruri were rightly collected in the month of August 2015 from the herbal garden of Hamdard University (Jamia Hamdard), New Delhi, India. The collected plant material was then authenticated by taxonomist "Dr. H.B Singh", Scientist G \& Head, Raw Materials Herbarium \& Museum, National Institute of Science Communication and Information Resources (NISCAIR), New Delhi, India. A well-preserved voucher specimen (PN/FP/DPP/032) was officially deposited in the museum of natural products, Pharmacognosy and Phytochemistry Department, Faculty of Pharmacy, Hamdard University, New Delhi, India. The authenticated samples were properly washed with distilled water, cut into small size pieces, well dried at room temperature and finally powdered by using a home grinder (Mixer Grinder MG-2753 Lexus Usha, India). The extraction was carried out using a supercritical fluid extractor Spe-edTM Prime (Applied Separation, USA). The dried powder of the sample $(20 \mathrm{~g})$ was transferred to an extraction vessel of $50 \mathrm{ml}$ capacity. The static extraction was initiated after achieving the required temperature and pressure. The air compressor was used to maintain the desired operating pressure. A glass vial having a rubber plug at the top was used to collect the final extract (Yield 7.5 $\%)$ ). The flow rate of $\mathrm{CO} 2$ was set aside at 1.0 $\mathrm{ml} / \mathrm{min}$ approximately by manual adjustment of the outlet valve. The obtained supercritical carbon dioxide extract was safely stored in the refrigerator at a temperature of $4{ }^{\circ} \mathrm{C}$ till further investigations.

\section{Preparation of $\boldsymbol{P}$. niruri extract}

The dried extract $\left(\mathrm{SC}-\mathrm{CO}_{2}\right)$ sample $(1 \mathrm{~g})$ was mixed with double distilled water $(100 \mathrm{ml})$ in a glass beaker and then properly filtered with Whatman filter paper no. 1. The resulted filtered solution was safely stored at an optimum temperature in a refrigerator for next studies.

\section{Synthesis of silver nanoparticles (AgNPs) by microwave method}

The silver nitrate (AgNO3) in the freshly prepared distilled water was utilized as a source of silver metal ions. In a typical microwave synthesis, 1 $\mathrm{mM}$ silver nitrate solution $(90 \mathrm{ml})$ was transferred into a $250 \mathrm{ml}$ capacity glass beaker. Next, $10 \mathrm{ml}$ of $P$. niruri extract $\left(\mathrm{SC}^{-} \mathrm{CO}_{2}\right)$ was transferred to this beaker and the resulting mixture was properly stirred for two minutes. This mixture was then placed in a microwave oven (Samsung MW$73 \mathrm{AD}-\mathrm{B}$ ) operating at $800 \mathrm{~W}$ of power and 2450 
$\mathrm{MHz}$ frequency. Subsequently, this solution was exposed to the microwave irradiations for the duration of 30, 60 and 90 seconds. The synthesis and formation of AgNPs were monitored by a UV-visible spectrophotometer. The reaction mixture was analyzed after 30,60 , and 90 seconds of the microwave action. The AgNPs solution was then put under centrifugation process at $25000 \mathrm{rpm}$ for the duration of 10 minutes. The obtained supernatant was removed and the Nanoparticles were re-dispersed in distilled water. The above process was performed in triplicate and so the obtained pure sample was then freeze-dried in order to get dry AgNPs.

\section{Characterization of silver nanoparticles}

\section{Ultraviolet-visible spectra analysis}

The freeze-dried AgNPs were subjected to the optical measurement which was performed by using ultraviolet-visible (UV-Vis) spectrophotometer (Shimadzu UV-2450, USA) and the scanning of the spectra was done between 200 - 800 nM 200 - 800 nM [10].

\section{Dynamic light scattering (DLS) zetasizer analysis}

The Zetasizer Nano instrument (Malvern Instruments, Nano ZS, ZEN3600, UK) operating with a $532 \mathrm{nM}$ laser was used to examine the distribution of the particle size of the newly synthesized AgNPs by dynamic light scattering (DLS). The required quantity of AgNPs was mixed with a little amount of distilled water to make a suspension of $1 \%$ concentration and this suspension was maintained at $37{ }^{\circ} \mathrm{C}$ with agitation at $100 \mathrm{rpm}$ [10].

\section{Transmission electron microscopy (TEM)}

The further characterization of the AgNPs was accomplished by the transmission electron microscopy (TEM). The TEM investigations for the measurements of size and shape were executed using a JEOL TEM-2010 instrument (Japan) having an inbuilt CCD photo recorder. This instrument was run at a voltage of $200 \mathrm{kV}$. With the help of the micro-syringe for TEM, a single drop of silver colloid of Nanoparticles was carefully kept on the copper grid coated carbon membrane and then allowed to dry at a normal room temperature for an hour [10].

\section{$X$-ray diffraction (XRD) analysis}

The X-ray diffraction (XRD) method was used to study the crystalline structure of the newly synthesized silver nanoparticles. The X-ray powder diffraction (XRD) data were analyzed with the help of the D/MAX-IIIC powder diffractometer (Physics Co.), which was operated in the $\theta: 2 \theta$ mode mainly in the $10-70 \circ(2 \theta)$ range and step-scan of $2 \theta=0.02^{\circ}$. The sample data was acquired by $\mathrm{Ni}$ filter and $\mathrm{Cu} \mathrm{Ka}$ radiation at $\lambda=0.15406 \mathrm{nM}$. The tube voltage and current were $36 \mathrm{kV}$ and $20 \mathrm{~mA}$, respectively [10].

\section{Fourier transform infrared (FTIR) spectroscopy}

The FTIR spectroscopy technique was used to acquire an infrared spectrum of emission or absorption of different materials. Nicolet Nexus 6700 FTIR spectrometer (with a Multi-Bounce ATR accessory with a ZnSe crystal) was used for the measurement of FTIR spectra. In this study, all spectra were measured at $2 \circ \mathrm{cm}-1$ resolution. Briefly, a little amount of the sample was kept on the top of the ATR crystal and set aside for some time to dry at normal room temperature to form the film. This prepared film was then analyzed [10].

\section{Antimicrobial assays \\ Preparation of test samples}

The test samples of $\mathrm{AgNO}_{3}$, Ag-NPs $(150 \mu \mathrm{g} / \mathrm{ml}$ each) and plant extract $(1500 \mu \mathrm{g} / \mathrm{ml})$ were prepared in DMSO (Dimethyl Sulfoxide) and were kept at a low temperature in the refrigerator for the study.

\section{Test microorganisms}

All the standard samples of microorganisms used in the current study were obtained from the National Chemical Laboratory (NCL), Pune, India. Different strains of bacteria and fungi were used for antimicrobial studies. The bacterial strains Escherichia coli, Klebsiella pneumonia, Pseudomonas aeruginosa, Staphylococcus aureus, Bacillus subtilis, Salmonella typhi, were included while fungal strains were Aspergillus niger and Candida albicans.

\section{Antimicrobial bioassay}

The antimicrobial activity of the synthesized AgNPs against the human pathogenic bacteria was investigated by the disc diffusion method as per the modified method of Manikandan et al [11]. The human pathogenic strain of bacteria was transferred into test tubes containing the sterile nutrient broth with the help of a sterile metal wire loop. The experimental test tubes 
were safely incubated for 24 hours at a temperature of $37{ }^{\circ} \mathrm{C}$. The test tubes were observed for the visible turbidity. These pathogens were absorbed on the surface of sterile cotton swab by dipping into the suspension. The sterile cotton swab was streaked on the whole surface of the medium plates containing Muller Hinton Agar. Then each test sample $(50 \mu \mathrm{L})$ was soaked separately on a paper disc (6 $\mathrm{mm}$ diameter) made up from Whatman filter paper (No. 1). These impregnated paper discs were ascetically transferred to the surface of the petri dish media. Streptomycin (10 $\mu \mathrm{g})$ and Ketoconazole $(10 \mu \mathrm{g})$ were used as reference antibacterial and antifungal drugs for comparison to the test samples, while DMSO was included in the study as a negative control. The inoculated plates were then safely incubated at a temperature of $37{ }^{\circ} \mathrm{C}$ for the duration of 24 hours in the case of bacteria, while the incubation period was 48 hours at $37^{\circ} \mathrm{C}$ in the case of fungi. The clear zone around the disc was considered as the zone of inhibition of microbial growth. The diameter of the inhibition zone was precisely determined to calculate the antibacterial activity of the test samples and standard drugs. The Antibacterial activity of the AgNPs against all the tests of human pathogenic microbial strains was further assessed by measuring the minimum inhibitory concentration (MIC) of the synthesized Nanoparticles. The MIC is the smallest concentration of the test samples (AgNPs) which inhibit the growth of microbes. The MIC of these AgNPs was measured by the micro broth dilution method with multi-well microliter culture plates having 96 wells with slight modifications [12]. Resazurin, a purple color indicator, was used for the assessment of the growth of the cells. The microbial cells alter the color of the resazurin from purple to pink/colorless by reducing it. The indicator's color remains purple in the absence of the living cells. The smallest concentration of the AgNPs was considered as MIC at which the color of the indicator changed.

\section{RESULTS}

\section{Synthesis of AgNPs and UV-Vis spectra}

The synthesis of silver Nanoparticles was visually confirmed by the change in the color of the reaction mixture as the microwave radiations progress. The color of the reactants was steadily changed from colorless to yellowish brown upon microwave irradiation. The UV-visible spectra of the reaction mixture documented at 30-second intervals are illustrated in Figure 1.

There was a peak at $415 \mathrm{nM}$ after exposure to radiation for 30 seconds. The intensity of the peak was found to be amplified with an increase in the reaction time without much change in the wavelength. The microwave synthesis was completed in just 90 seconds. The band was observed at $415 \mathrm{nM}$, which has occurred due to an intense surface plasmon resonance (SPR) of the newly synthesized AgNPs. The peak was approximately symmetrical and no peaks were seen in the range of $450-800 \mathrm{nM}$.

\section{Particle size}

In Zetasizer analysis, there was an intense peak between 100 - $200 \mathrm{~nm}$. The AgNPs had a mean size of $110 \mathrm{~nm}$ (Figure 2).

\section{TEM images}

The transmission electron microscopy (TEM) images were taken to examine the size and shape of the newly synthesized AgNPs. The histogram of AgNPs showing particle size distribution is given in Figure 3 . The particle size ranged from $50 \mathrm{~nm}$ to $150 \mathrm{~nm}$ and had a mean size of $110 \mathrm{~nm}$.

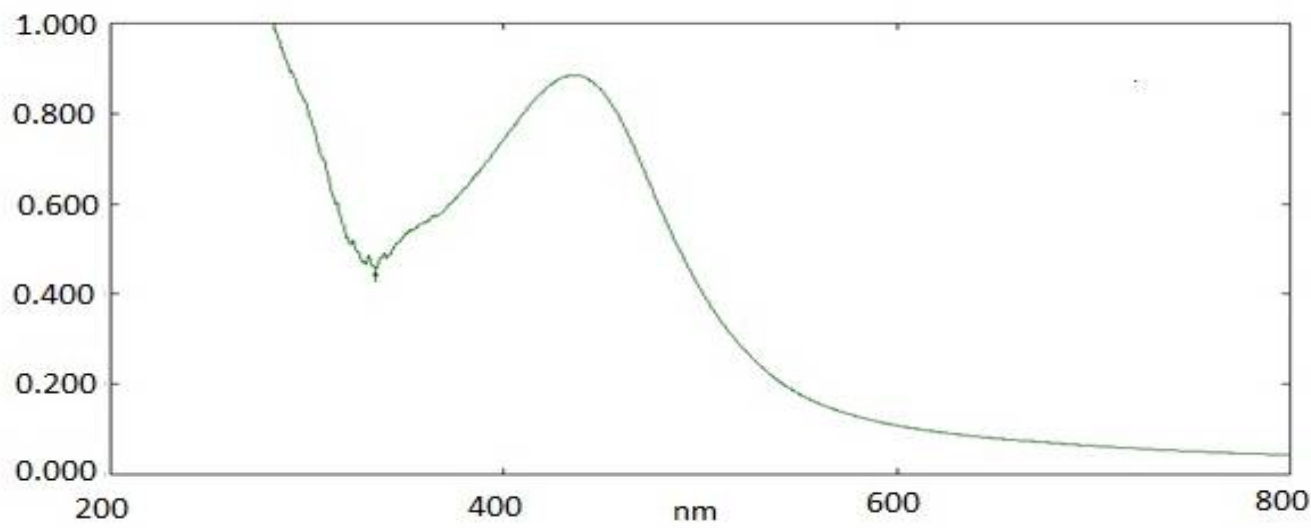

Figure 1: UV-visible absorption spectra for prepared AgNPs 


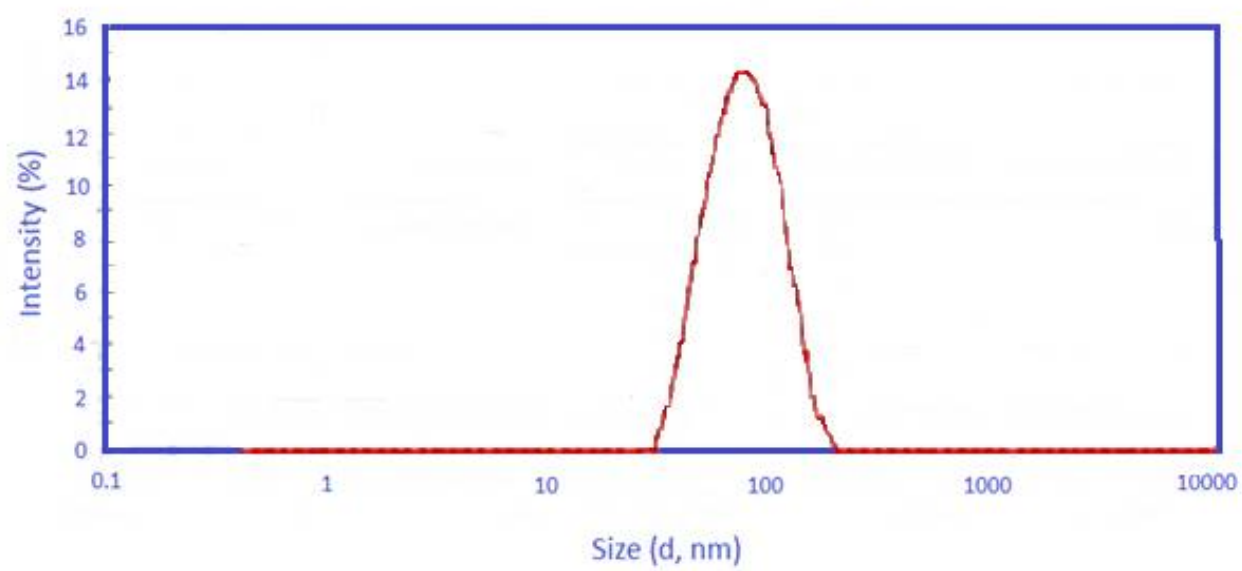

Figure 2: DLS zetasizer data for silver nanoparticles

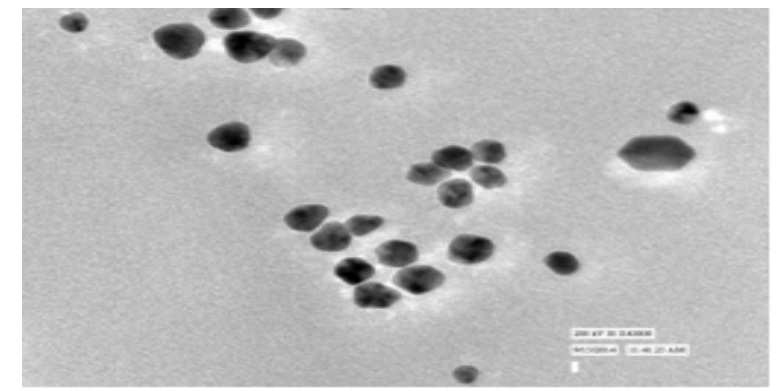

Figure 3: TEM analysis of silver nanoparticles

\section{X-ray diffractograms}

The X-ray diffraction (XRD) analysis of the synthesized silver nanoparticles was carried out to investigate the crystal structure of these nanoparticles. The XRD pattern of the AgNPs is presented in Figure 4.

There were many strong Bragg reflection peaks viewed at $38.17^{\circ}, 44.28^{\circ}$ and $64.52^{\circ}$, corresponding to [111], [200] and [220] planes of pure silver. The obtained data were compared with the literature data (JCPDS, File No. 4-0783). It was revealed that all these peaks in the X-ray diffraction (XRD) pattern are corresponding to a face-centered cubic (FCC) structure of the silver. It confirmed the core composition of the synthesized AgNPs. The analysis of the pattern of XRD diffractograms apparently proved the crystalline nature of the prepared AgNPs. The other peaks are due to the presence of carbon, which comes from the biomaterial. The peak at the [111] plane was highly intense, while other peaks at the [200] and [220] planes were comparatively of low intensity. The crystal size of the prepared AgNPs was established through the full-width at half maximum (FWHM) of the highintensity diffraction peak by adopting the Scherrer's formula as in Eq 1 [15].

$D=0.9 N \beta \cos \theta$

where, $\mathrm{D}=$ Mean crystalline area size perpendicular to the reflecting planes, $\lambda=$ Wavelength of X-ray, $\beta=$ FWHM of diffraction peak, $\theta=$ Diffraction angle. The mean estimated crystallite size of the present AgNPs was 110 nm.

\section{FT-IR spectra}

The FTIR spectroscopy was done for the identification of functional groups present in the phytochemicals/biomolecules in the extract.

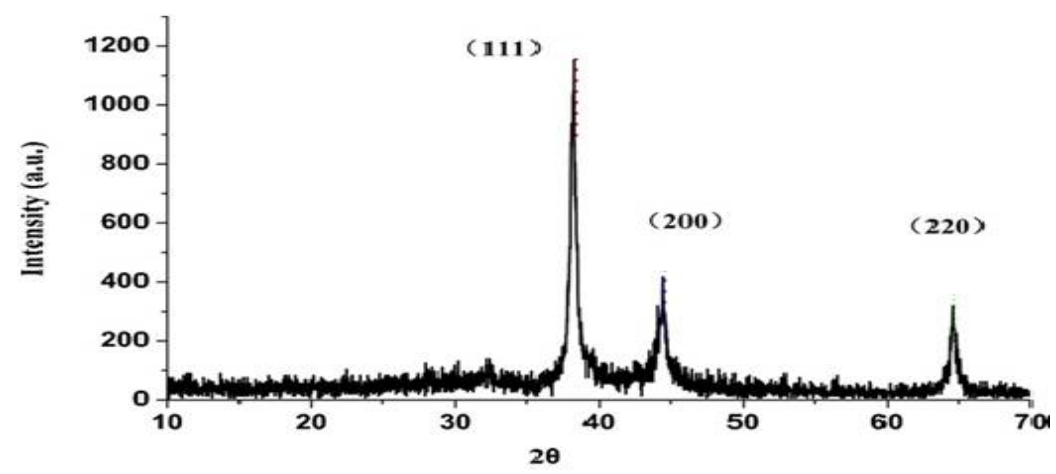

Figure 4: X-ray diffractograms of synthesized silver nanoparticles (AgNPs) 
These phytochemicals/biomolecules are mainly helping in the capping and stability of the AgNPs. The infrared spectra of the synthesized AgNPs showed the absorption peaks at 3417, 2924, 1642, 1411, 1031, and $774 \mathrm{~cm}^{-1}$ (Figure 5). The alcoholic $\mathrm{O}-\mathrm{H}$ stretching vibration, and aldehydic $\mathrm{C}-\mathrm{H}$ stretching vibration was assigned to the bands at $3417 \mathrm{~cm}^{-1}$ and $2924 \mathrm{~cm}^{-1}$, respectively.

\section{Antibacterial activity of AgNPs}

The antimicrobial activity of AgNPs was evaluated by a micro-broth dilution method. The final results of this study showed that AgNPs derived from the $P$. niruri extract exhibited the broad spectrum antimicrobial potential against several gram-negative bacteria and grampositive bacteria including plant and human pathogenic fungi. The results of this study demonstrated that the antimicrobial action of AgNPs prepared from the extract was shown to be very significant against all the bacterial as well as fungal ATCC strains, whereas the plant extract did not demonstrate the significant antimicrobial activity even at a 10 times higher concentration than AgNPs. It was also revealed in our study that the antimicrobial activities of AgNPs were found to be higher in comparison to the streptomycin (Standard antibacterial drug) against bacteria, ketoconazole (Standard antifungal drug) and against fungi (Table 1).

While the minimum inhibitory concentration (MIC) of silver nanoparticle (AgNPs) was within the range of $3.12-25 \mu \mathrm{g} / \mathrm{ml}$ against all tested microbes (Figure 6).

\section{DISCUSSION}

The formation of silver nanoparticle (AgNPs) was visually confirmed by the change in the color of the reaction mixture as the microwave radiation progressed. The color of the reactants was steadily changed from colorless to yellowish brown upon microwave irradiation. The UV-vis spectra of the reaction mixture documented at 30 -second intervals is shown in Figure 1. There was a peak at $415 \mathrm{nM}$ after exposing it to radiation for $30 \mathrm{~s}$. The intensity of the peak was

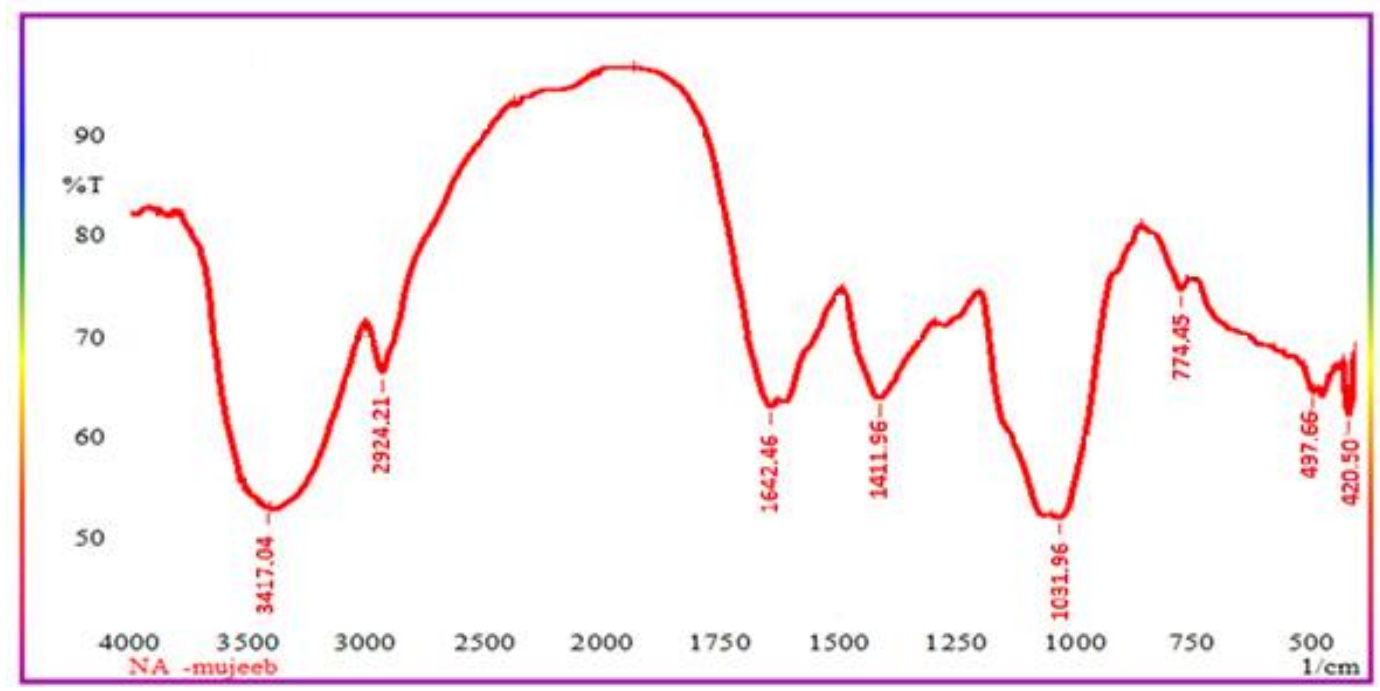

Figure 5: Fourier transform infrared spectroscopy (FT-IR) spectra of synthesized AgNPs

Table 1: Zone of inhibition induced by nanoparticles

\begin{tabular}{|c|c|c|c|c|}
\hline \multirow[b]{2}{*}{ Microbe } & \multicolumn{4}{|c|}{ Zone of inhibition (mm) } \\
\hline & $\begin{array}{l}\text { SFE Extract } \\
(1500 \mu \mathrm{g} / \mathrm{ml})\end{array}$ & $\begin{array}{c}\mathrm{AgNO}_{3} \\
(150 \mu \mathrm{g} / \mathrm{ml})\end{array}$ & $\begin{array}{c}\text { AgNPs } \\
(150 \mu g / m l)\end{array}$ & $\begin{array}{l}\text { Positive control } \\
(10 \mu \mathrm{g} / \mathrm{ml})\end{array}$ \\
\hline Staphylococcus aureus & $5 \pm 0.18$ & $13 \pm 0.34$ & $15 \pm 0.12$ & $12 \pm 0.11$ \\
\hline Basillus subtilis & NIL & $14 \pm 0.63$ & $18 \pm 0.52$ & $10 \pm 0.26$ \\
\hline Salmonella typhi & NIL & $11 \pm 0.46$ & $14 \pm 0.57$ & $10 \pm 0.67$ \\
\hline Escherichia coli & $6 \pm 0.24$ & $16 \pm 0.87$ & $20 \pm 0.93$ & $13 \pm 0.43$ \\
\hline Pseudomonas aeruginosa & NIL & $15 \pm 0.76$ & $19 \pm 0.67$ & $11 \pm 0.56$ \\
\hline Klebsiella pneumonia & $8 \pm 0.54$ & $13 \pm 0.56$ & $17 \pm 0.60$ & $10 \pm 0.52$ \\
\hline Candida albicans & $4 \pm 0.15$ & $15 \pm 0.32$ & $18 \pm 0.63$ & $12 \pm 0.88$ \\
\hline Aspergillus niger & NIL & $18 \pm 0.52$ & $24 \pm 0.70$ & $14 \pm 0.66$ \\
\hline
\end{tabular}

SFE = supercritical fluid extract, AgNO3 = silver nitrate extract, AgNPs = silver nanoparticles extract Positive control = streptomycin (for bacteria) and ketoconazole (for fungi) 


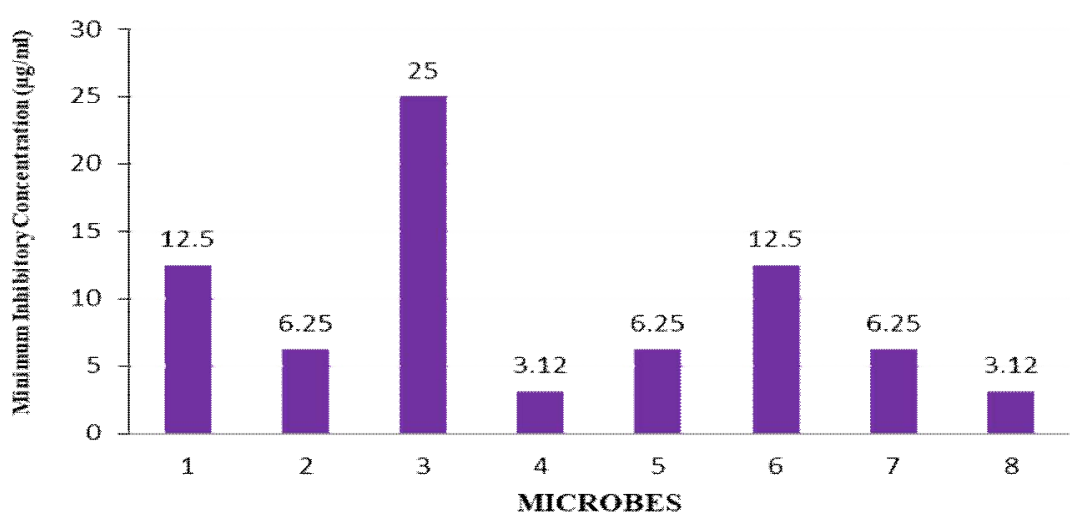

Figure 6: Minimum inhibition concentration of AgNPs against ATCC bacterial and fungal strains, 1= Staphylococcus aureus, 2= Bacillus subtilis, 3= Salmonella typhi, 4= Escherichia coli, 5= Pseudomonas aeruginosa, $6=$ Klebsiella pneumonia, $7=$ Candida albicans, $8=$ Aspergillus niger

found to be amplified with an increase in the reaction time without much change in the wavelength. The microwave synthesis was completed in just $90 \mathrm{~s}$. The band was observed at $415 \mathrm{nM}$, which has occurred due to an intense surface plasmon resonance of the newly synthesized AgNPs. The peak was approximately symmetrical and no peaks were seen in the range of $450-800 \mathrm{nM}$, this indicates that there are no aggregations between the AgNPs [13]. The net vibration in the conduction of the electrons of nanoparticles by visible light results in the formation of the SPR band and this SPR band is greatly affected by the size and shape of the nanoparticles [14]. It was revealed by the UV-visible spectral studies that nanoparticles are almost of spherical shape and are uniformly distributed. The advantage of the microwave synthesis is that it produces small, uniform-sized nanoparticles in a minimum reaction time. The rapid utilization of starting materials, decreased the development of agglomerates in the microwave assisted methods and provides nanoparticles with narrow size distribution. As stated earlier, the extract of $P$. niruri is rich in various phytochemicals like tannins, terpenoids, and flavonoids such as kaempferol, quercetin, and phyllanthin. The $P$. niruri extract was mixed with the $\mathrm{AgNO}_{3}$ solution to form silver nanoparticles. The flavonoid contents of the extract efficiently reduce the $\mathrm{Ag}^{+}$ ions into $\mathrm{Ag}$ atoms that in turn unite to form AgNPs. The phytochemicals present in the $P$. niruri extract also works as capping agents, thus these phytochemicals prevent the agglomeration of the nanoparticles and help to stabilize and protect the nanoparticles. The Zetasizer analysis is an important tool for the characterization of AgNPs. There was an intense peak between 100 - $200 \mathrm{nM}$. The AgNPs had a mean size of 110 $\mathrm{nm}$ (Figure 2). The measurement of zeta potential on the AgNPs exhibited the negative surface charge of the newly synthesized AgNPs. The negative surface charge generated the repulsive forces among the AgNPs that reduced the aggregation of AgNPs [15]. The transmission electron microscopy (TEM) analysis also confirmed the formation of AgNPs. The TEM investigation of the synthesized AgNPs was done to analyze the particle size and shape of the AgNPs. TEM is a very useful and unique technique to examine the size and shape of the AgNPs. The histogram of AgNPs showing the distribution of particle size is given in Figure 3. TEM images revealed the spherical shape of synthesized AgNPs. The particle size of AgNPs was ranged from $50 \mathrm{~nm}$ to $150 \mathrm{~nm}$ with a mean size of $110 \mathrm{nM}$. The smaller size and spherical shape of AgNPs have many advantages in drug delivery and their numerous applications in biological and other sciences. For instance, the smaller and spherical AgNPs can easily through the cell membrane as compared to the larger particles. The improved penetration capability of the smaller spherical particles will enhance the therapeutic potential of the AgNPs [15]. The Xray diffraction (XRD) investigations of the synthesized silver nanoparticles were also accomplished to investigate the structure of these nanoparticles. The XRD pattern of the AgNPs is presented in Figure 4. Many strong Bragg reflection peaks were viewed at $38.17^{\circ}$, $44.28^{\circ}$ and $64.52^{\circ}$, corresponding to [111], [200] and [220] planes of pure silver. The obtained data were compared with the literature data (JCPDS, File No. 4-0783). It was revealed that all these peaks in the XRD pattern are corresponding to a face-centered cubic (FCC) structure of silver. It confirmed the core composition of the synthesized AgNPs. The analysis of the pattern of an XRD diffractograms apparently proved the crystalline nature of the prepared AgNPs. The other peaks are due to the presence of carbon, which comes from the 
Biomaterial. The peak at the [111] plane was highly intense, while other peaks at the [200] and [220] planes were comparatively of low intensity. The crystal size of the prepared AgNPs was established through the full-width at half maximum (FWHM) of the high-intensity diffraction peak. The estimated mean size of the present AgNPs was $110 \mathrm{~nm}$. Overall, the XRD investigations confirm the crystalline structure of the prepared AgNPs [16]. The FTIR spectroscopy was done for the identification of functional groups present in the phytochemicals/biomolecules in the extract. These phytochemicals/biomolecules are mainly helping in the capping and stability of the AgNPs. The infrared spectra of the synthesized AgNPs showed the absorption peaks at 3417, 2924, 1642, 1411, 1031, and $774 \mathrm{~cm}^{-1}$ (Figure 5). The alcoholic $\mathrm{O}-\mathrm{H}$ stretching vibration, and aldehydic, the $\mathrm{C}-\mathrm{H}$ stretching vibration was assigned to the bands at $3417 \mathrm{~cm}^{-1}$ and $2924 \mathrm{~cm}^{-1}$, respectively. The band at $1642 \mathrm{~cm}^{-1}$ might be attributable to the $\mathrm{C}=\mathrm{C}$ aromatic vibrations [17]. The band (1031 $\mathrm{cm}^{-1}$ ) might be contributing to the C-N stretching vibration of the aliphatic amine [18]. The band at $\left(774 \mathrm{~cm}^{-1}\right)$ indicates the existence of an alkyl halide. The IR spectral data gave a hint that the presence of $\mathrm{OH}$ group in the extract might lead to the reduction of $\mathrm{Ag}+$ to $\mathrm{AgO}$ by the method of oxidation of alcohol to aldehyde group. It was also confirmed by the FTIR analysis that the carbonyl group of proteins and amino acids is quite capable of binding with AgNPs and thus could make a layer on the outer surface of AgNPs. Hence, the surface capped biomolecules (proteins and amino acids) might have stopped the agglomeration and thus maintained the stability of the AgNPs. This has been proposed that the secondary plant metabolites might be responsible for both reducing as well as stabilizing the activities of AgNPs [19]. The Antibacterial activity of the synthesized AgNPs was performed to investigate their potential use as an antibacterial agent against some pathogenic strains of bacteria and fungi. The silver is commonly used as a therapeutic agent for the prevention and treatment of various diseases in some traditional medical system like Ayurveda, Siddha and Unani etc. The silver at a low concentrations is considered as non-toxic to the human body. This is also a known fact that $\mathrm{Ag}+$ ions produce lethal toxicity to microorganisms. Therefore, AgNPs are considered as an excellent candidate for the antimicrobial therapy. AgNPs reported to possess broad-spectrum antibacterial activities against a wide range of bacterial species. The metallic silver as nanoparticles (AgNPs) has been known to possess antimicrobial potential against various infectious diseases. The silver ion concentration in the solution is directly proportional to its antimicrobial activity [20]. In the past few decades, the emerging trends of antibiotic resistance were a challenge to the global scientific community. In the current scenario, AgNPs have emerged as an excellent antibacterial agent that is attributable to their exceptionally small size and other properties. In the present investigations, the antimicrobial activity of AgNPs was carried out by the micro broth dilution method. The results of our study showed that the AgNPs derived from the $P$. niruri extract, exhibited the broad spectrum antimicrobial activities against several gramnegative bacteria and gram-positive bacteria including the pathogenic fungi. The AgNPs exhibited excellent antimicrobial activities which might be attributed to their very large surface area which in turn offer an enhanced contact area to the pathogenic microorganisms. These AgNPs are known to liberate silver ions directly into the bacterial cells, which is responsible for their bactericidal activities [21]. The AgNPs exhibited the oligodynamic effects (biocidal effect) due to their silver ions. The silver ions of AgNPs cause alteration in the cell membrane permeability, inhibits the DNA replication and denaturation of the cellular proteins. Although, the exact mechanism of the antimicrobial activity of AgNPs has not been clearly explained so far, a number of possible mechanisms of antimicrobial action of AgNPs have been postulated. The silver ions liberated from the AgNPs of the extract play vital role in the bactericidal effect of the bacteria. The silver ions which are released from the AgNPs are believed to interact with the negatively charged bacterial cell, leading to rupture of the bacterial cell which ultimately cause a denaturation of protein and eventually cell death [22]. AgNPs is also known for destabilization of the outer membrane of the microbial cell causing damage to the plasma membrane, which leads to the diminution of intracellular ATP [23]. Some other possible mechanism of the antimicrobial actions includes the interaction of silver with the oxygen and their reaction with sulfhydryl $(-\mathrm{S}-\mathrm{H})$ groups on the cell wall of microbes which leads to the formation of $\mathrm{R}-\mathrm{S}-\mathrm{S}-\mathrm{R}$ bonds that result in the blocking of respiration and ultimately cell death [24]. In many other studies, it was reported that the positive charge on the $\mathrm{Ag}+$ ions play a vital role in the antimicrobial activity of AgNPs. It has been postulated that the positively charged $\mathrm{Ag}+$ ions of AgNPs interact with the negatively charged cell membrane of the microorganisms which results in the death of the microbial cell [25]. In the study undertaken, we have compared the antimicrobial properties of synthesized AgNPs to their extract. The results of this study demonstrated that the 
antimicrobial action of AgNPs prepared from the extract was shown to be very significant against all bacterial as well as the fungal ATCC strains, whereas the plant extract did not demonstrate the significant antimicrobial activity even at 10 times more concentration than the AgNPs. It was also revealed in our study that the antimicrobial activities of AgNPs were found to be higher in comparison to the streptomycin (Standard antibacterial drug) against bacteria and ketoconazole (Standard antifungal drug) against fungi (Table 1). The MIC of AgNPs was within a range of $3.12-25 \mu \mathrm{g} / \mathrm{ml}$ against all the tested microbes (Figure 6). In addition to this, the synthesized AgNPs of this plant extract augments the therapeutic potential and folklore uses of the plant when used along with silver.

\section{CONCLUSION}

The current study demonstrated a novel technique with a simple, eco-friendly, costeffective, innovative approach for the rapid green synthesis of AgNPs of the herbal extract. We have efficiently synthesized that the AgNPs is derived from a supercritical carbon dioxide extract of the fresh aerial parts of Phyllanthus niruri $\mathrm{L}$. The X-ray diffraction (XRD) and TEM images have confirmed the crystal size and shape of AgNPs. The FTIR analysis, UV-visible spectroscopy, and zeta potential have authenticated the stability of the AgNPs. Furthermore, These AgNPs also exhibited good antimicrobial activities against several tested pathogenic microbes. Hence, the synthesized AgNPs might play a valuable role in a number of biomedical utilization.

\section{DECLARATIONS}

\section{Acknowledgement}

The authors are grateful to the Head, Department of Pharmacognosy and Phytochemistry, Jamia Hamdard, New Delhi, India for providing necessary research facilities to carry out this project.

\section{Conflict of interest}

The authors declare that there is no conflict of interest associated with this work.

\section{Contribution of authors}

The authors declare that this work was done by the authors named in this article and all liabilities pertaining to claims relating to the content of this article will be borne by them.

\section{REFERENCES}

1. Arokiyaraj S, Arasu MV, Vincent S, Prakash NU, Choi $\mathrm{SH}$, Oh YK, Choi KC, Kim KH. Rapid green synthesis of silver nanoparticles from Chrysanthemum indicum $L$ and its antibacterial and cytotoxic effects: an in vitro study. Int J Nanomedicine. 2014; 9: 379-788.

2. Chung IM, Park I, Seung-Hyun K, Thiruvengadam M, Rajakumar G. Plant-Mediated Synthesis of Silver Nanoparticles: Their Characteristic Properties and Therapeutic Applications. Nanoscale Res Lett. 2016; 11(1): 40.

3. Iravani $S$, Korbekandi $H$, Mirmohammadi SV, Zolfaghari $B$. Synthesis of silver nanoparticles: chemical, physical and biological methods. Res Pharm Sci. 2014; 9(6): 385-406.

4. Abbasi E, Milani M, Fekri Aval S, Kouhi M, Akbarzadeh A, Tayefi Nasrabadi H, Nikasa P, Joo SW, Hanifehpour $Y$, Nejati-Koshki K, Samiei $M$. Silver nanoparticles: Synthesis methods, bio-applications and properties. Crit Rev Microbiol. 2016; 42(2): 173-180.

5. Nadagouda MN, Speth TF, Varma RS. Microwaveassisted green synthesis of silver nanostructures. Acc Chem Res. 2011; 44(7): 469-478.

6. Singh $H, D u J$, Singh P, Yi TH. Ecofriendly synthesis of silver and gold nanoparticles by Euphrasia officinalis leaf extract and its biomedical applications. Artif Cells Nanomed Biotechnol. 2017; 8: 1-8.

7. Patil MP, Kim GD. Eco-friendly approach for nanoparticles synthesis and mechanism behind antibacterial activity of silver and anticancer activity of gold nanoparticles. Appl Microbiol Biotechnol.2017; 101(1):79-92.

8. Lee NY, Khoo WK, Adnan MA, Mahalingam TP, Fernandez AR, Jeevaratnam $K$. The pharmacological potential of Phyllanthus niruri. J Pharm Pharmacol. 2016; 68(8): 953-969.

9. Klein-Júnior $L C$, da Silva $L M$, Boeing $T$, Somensi $L B$, Beber AP, Rocha JA, Henriques AT, Andrade SF, Cechinel-Filho $V$. The Protective Potential of Phyllanthus niruri and Corilagin on Gastric Lesions Induced in Rodents by Different Harmful Agents. Planta Med. 2017; 83(1-02): 30-39.

10. Sathiya CK, Akilandeswari S. Fabrication and characterization of silver nanoparticles using Delonix elata leaf broth. Spectrochim Acta A Mol Biomol Spectrosc. 2014; 128: 337-341.

11. Manikandan $R$, Manikandan $B$, Raman $T$, Arunagirinathan K, Prabhu NM, Jothi Basu M, Perumal M, Palanisamy S, Munusamy A. Biosynthesis of silver nanoparticles using ethanolic petals extract of Rosa indica and characterization of its antibacterial, anticancer and anti-inflammatory activities. Spectrochim Acta A Mol Biomol Spectrosc. 2015 5; 138: 120-129.

12. Sarker SD, Nahar L, Kumarasamy Y. Microtitre platebased antibacterial assay incorporating resazurin as an indicator of cell growth, and its application in the in vitro 
antibacterial screening of phytochemicals. Methods. 2007; 42(4): 321-324.

13. Muniyan A, Ravi K, Mohan U, Panchamoorthy $R$. Characterization and in vitro antibacterial activity of saponin-conjugated silver nanoparticles against bacteria that cause burn wound infection. World I Microbiol Biotechnol. 2017; 33(7): 147.

14. Link S, El-Sayed MA. Optical properties and ultrafast dynamics of metallic nanocrystals. Annu Rev Phys Chem. 2003; 54: 331-366.

15. Padalia H, Moteriya $P$, Chanda S. Green synthesis of silver nanoparticles from marigold flower and its synergistic antimicrobial potential. Arab. J. Chem. 2015; 8(5): 732-741.

16. Klug HP, Alexander LE. X-Ray diffraction procedures for polycrystalline and amorphous materials. New York, Wiley, 2nd Edn. 1974, 491 p. ISBN, 978-0-471-49369-3

17. Chandran SP, Chaudhary M, Pasricha R, Ahmad A, Sastry M. Synthesis of gold nanotriangles and silver nanoparticles using Aloe vera plant extract. Biotechnol Prog. 2006; 22(2): 577-583.

18. Sathyavathi R, Krishna MB, Rao SV, Saritha R, Rao $D N$. Biosynthesis of silver nanoparticles using Coriandrum sativum leaf extract and their application in nonlinear optics. Adv Sci Lett. 2010; 3(2): 138-143.

19. Roy N, Mondal S, Laskar RA, Basu S, Mandal D, Begum NA. Biogenic synthesis of $A u$ and Ag nanoparticles by Indian propolis and its constituents. Colloids Surf $B$ Biointerfaces. 2010 1; 76(1): 317-325.
20. Baker C, Pradhan A, Pakstis L, Pochan DJ, Shah SI. Synthesis and antibacterial properties of silver nanoparticles. J Nanosci Nanotechnol. 2005; 5(2): 244249.

21. Feng QL, Wu J, Chen GQ, Cui FZ, Kim TN, Kim JO. A mechanistic study of the antibacterial effect of silver ions on Escherichia coli and Staphylococcus aureus. J Biomed Mater Res. 2000; 52(4): 662-668.

22. Rodríguez-León $E$, Iñiguez-Palomares $R$, Navarro $R E$, Herrera-Urbina $R$, Tánori J, Iñiguez-Palomares $C$, Maldonado A. Synthesis of silver nanoparticles using reducing agents obtained from natural sources (Rumex hymenosepalus extracts). Nanoscale Res Lett. 2013; 8(1): 318

23. Lok CN, Ho CM, Chen R, He QY, Yu WY, Sun H, Tam $P K$, Chiu JF, Che CM. Proteomic analysis of the mode of antibacterial action of silver nanoparticles. $J$ Proteome Res. 2006; 5(4): 916-924.

24. Kumar VS, Nagaraja BM, Shashikala V, Padmasri AH, Madhavendra SS, Raju BD, Rao KSR. Highly efficient Ag/C catalyst prepared by electro-chemical deposition method in controlling microorganisms in water. $\mathrm{J} \mathrm{Mol}$ Catal A: Chem. 2004; 223(1-2): 313-319.

25. Cho KH, Park JE, Osaka T, Park SG, The study of antimicrobial activity and preservative effects of nanosilver ingredient. Electrochimica Acta. 2005; 51(5): 956-960. 